\title{
ANOTACIONES SOBRE EL USO DEL CLORHIDRATO DE AMITRIPTILINA EN LA CONDUCCION DEL TRABAJO DE PARTO*
}

Doctores Jaime Salazar Páez, Germán Navarro, Guillermo Bernal Domínguez, Otto Uscher c.

La búsqueda de substancias que posean acción ocitócica y sedante, a la vez que una baja toxicidad y facilidad para su administración, ha sido una de las metas investigativas más deseadas y menos frecuentemente logradas. Sin presumir que hemos llegado a ella, esperamos contribuír a su consecución.

A partir de experimentaciones sobre derivados iminodibencílicos (3), hemos observado con alguna amplitud el efecto de uno de ellos en parturientas a término. Para el caso escogimos el clorhidrato de amitriptilina, debido a que los informes clínicos y experimentales lo señalan como con mayor capacidad depresora nerviosa que los otros compuestos de este grupo, y los datos de farmacología experimental (3) indican que posee una actividad ocitócica más notoria.

* Comunicación al Congreso Colombiano de Obstetricia y Ginecología. Medellín, diciembre de 1963.

\section{MATERIAL Y METODOS}

$1 \overline{8} 0$ mujeres recibidas en el Hospital Universitario San Ignacio, con embarazo a término (39 semanas en promedio) y con edades oscilando entre 21 y 32 años, divididas en tres grupos:

a) Controles, sin drogas.

b) Quienes recibieron ocitocina como única droga.

c) Quienes recibieron amitriptilina como única droga.

Ocitocina y amitriptilina se administraron siempre cuando la dilatación del cuello llegaba a los $4 \mathrm{~cm}$ y las observaciones son hechas a partir de este momento. La ocitocina se aplicó en perfusión iv. por goteo; la amitriptilina, a la dosis individual de $30 \mathrm{mg}$ en una inyección iv., sin diluír. El registro toco- 
quimográfico se obtuvo con el parturiógrafo de Malmströn-Thorén y siguiendo la técnica de Corday (2). La valoración de sedación en la madre y vitalidad en el niño se hicieron clínicamente; para la segunda se empleó el método de Apgar. A todos los niños se les verificaron los controles de rutina.

\section{DISCUSION}

La distribución para paridad en los tres grupos muestran que el mayor número de primigestantes está entre las parturientas que recibieron amitriptilina, y la mayor de las multigestantes, en el grupo de controles. Es sabido que las multigestantes hacen un trabajo menos largo que las primigestantes, pero en estos resultados encontramos lo contrario: el grupo con mayoría de primigestantes, que fue el tratado con amitriptilina, hizo un trabajo con duración promedio de $8.20 \mathrm{H}$. frente al grupo de control (predominio de multigestantes), con duración promedio de $12.35 \mathrm{H}$.

Caldeyro y Alvarez (1) relievan la importancia de la aminiorrexis para acelerar y regularizar el trabajo de parto. En nuestras observaciones encontramos que las dos terceras partes de las pacientes que recibieron amitriptilina tenían las menbranas íntegras cuando el cuello estaba en $4 \mathrm{~cm}$ de dilatación, mientras que menos de la mitad de los controles estaban en condiciones iguales.

Teniendo en cuenta que el grupo con amitriptilina estaba en condiciones (membranas, paridad) para que corrientemente tuvieran un trabajo de parto más duradero que el grupo de control, pero que dicho trabajo fue más cor- to en aquél que en éste, y que las gráficas del tocoquimógrafo mostraron contracciones más intensas después de aplicar la amitriptilina, a la vez que algunas pacientes con esta droga ofrecieron una moderada sedación, creemos que con ella obtenemos parciaimente lo enunciado al principio de esta comunicación: un medicamento de cómoda administración y con acciones ocitócicas y sedantes.

\section{CONCLUSIONES}

La amitriptilina acelera el trabajo de parto en gestantes a término, mejorando la amplitud y el ritmo de las contracciones.

La amitriptilina provoca sedación moderada no constante.

No se observaron modificaciones de la vitalidad del feto, valorada por el sistema Apgar.

No se presentaron modificaciones con el empleo de esta substancia, recordándose que sus contraindicaciones son las de los anticolinérgicos.

\section{RESULTADOS}

Por grupos, la duración total del trabajo fue la siguiente:

$$
\begin{aligned}
& \text { Grupo a), } 12.35 \mathrm{~h} . \\
& \text { Grupo b), } 11.15 \mathrm{~h} . \\
& \text { Grupo c), } 8.20 \mathrm{~h} .
\end{aligned}
$$

En vista de lo heterogéneo de cada uno de estos grupos se hizo una distribución de acuerdo con la paridad y el estado de las membranas. Esto arroja los siguientes resultados horas de trabajo: 
Vol. $\mathbf{X V}$

No 5

\section{Grupo}

1 para 0

2 para $0-1$

Multíparas

LA AMITRIPTLINA EN EL TRABAJO

\section{Control}

16.05 H. (11)

$12.15 \mathrm{H} . \quad(8)$

$10.30 \mathrm{H} .(41)$

\section{Ocitocina}

$$
\begin{array}{rr}
14.15 & \text { H. } \\
12.55 & \text { H. } \\
9.42 & \text { H. } \\
9 & (35)
\end{array}
$$

Amitriptilina

$$
\begin{array}{r}
11.30 \text { H. (21) } \\
8.45 \text { H. (7) } \\
6.32 \text { H. (32) }
\end{array}
$$

(Entre paréntesis está el número de casos).

El estado de las membranas para cada grupo, cuando el cuello estaba en $4 \mathrm{~cm}$ de dilatación (momento de la aplicación de las drogas), se distribuye de la siguiente manera:

\begin{tabular}{lccc}
\hline & No de controles & No con ocitocina & $\begin{array}{c}\text { No con } \\
\text { amitriptilina }\end{array}$ \\
\hline M. rotas & 35 & 32 & 20 \\
M. íntegras & 25 & 28 & 40 \\
\hline
\end{tabular}

Las figuras 1, 2 y 3 reproducen gráficamente estos datos.

DURACION DEL TRABAJO EN HORAS

POR GRUPOS DE DROGAS. -

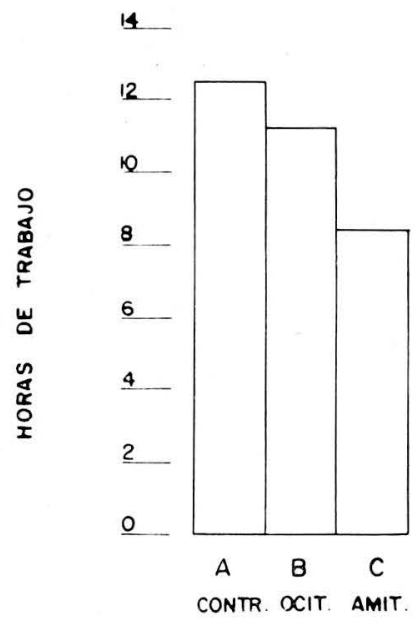


ESTADO DE LAS MEMBRANAS CON DILATACION DE $4 \mathrm{cms}$ -

DISTRIQUCION POR GRUPOS DE DROGAS -

40
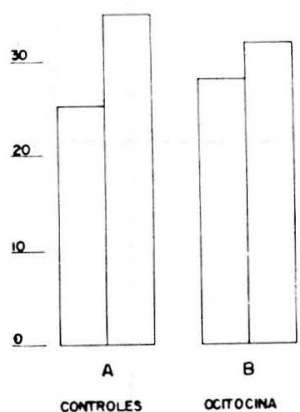

B

OCT OCINA

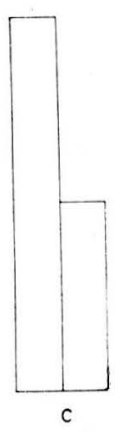

MarTRIPTILINA
Los registros tocoquimográficos (figuras 4,5 y 6) muestran, después de un período de latencia inferior a 10 minutos, un aumento de la altura del trazado en el momento de la contracción y una regularización del mismo.
OURACION OCL TMAQux EN HORAS.

nom canpos of PaRidad
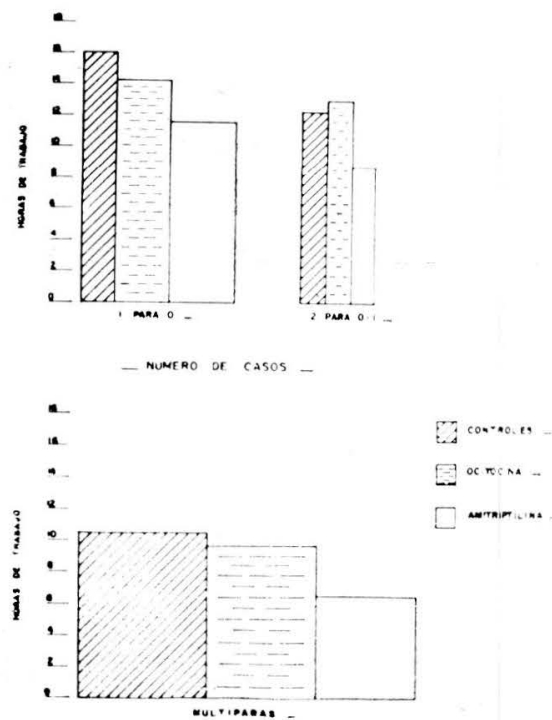

En algunas pacientes que recibieron amitriptilina, apareció sedación moderada.

Los resultados en la valoración de la vitalidad en los niños (Apgar) fue similar en todos los casos estudiados. 

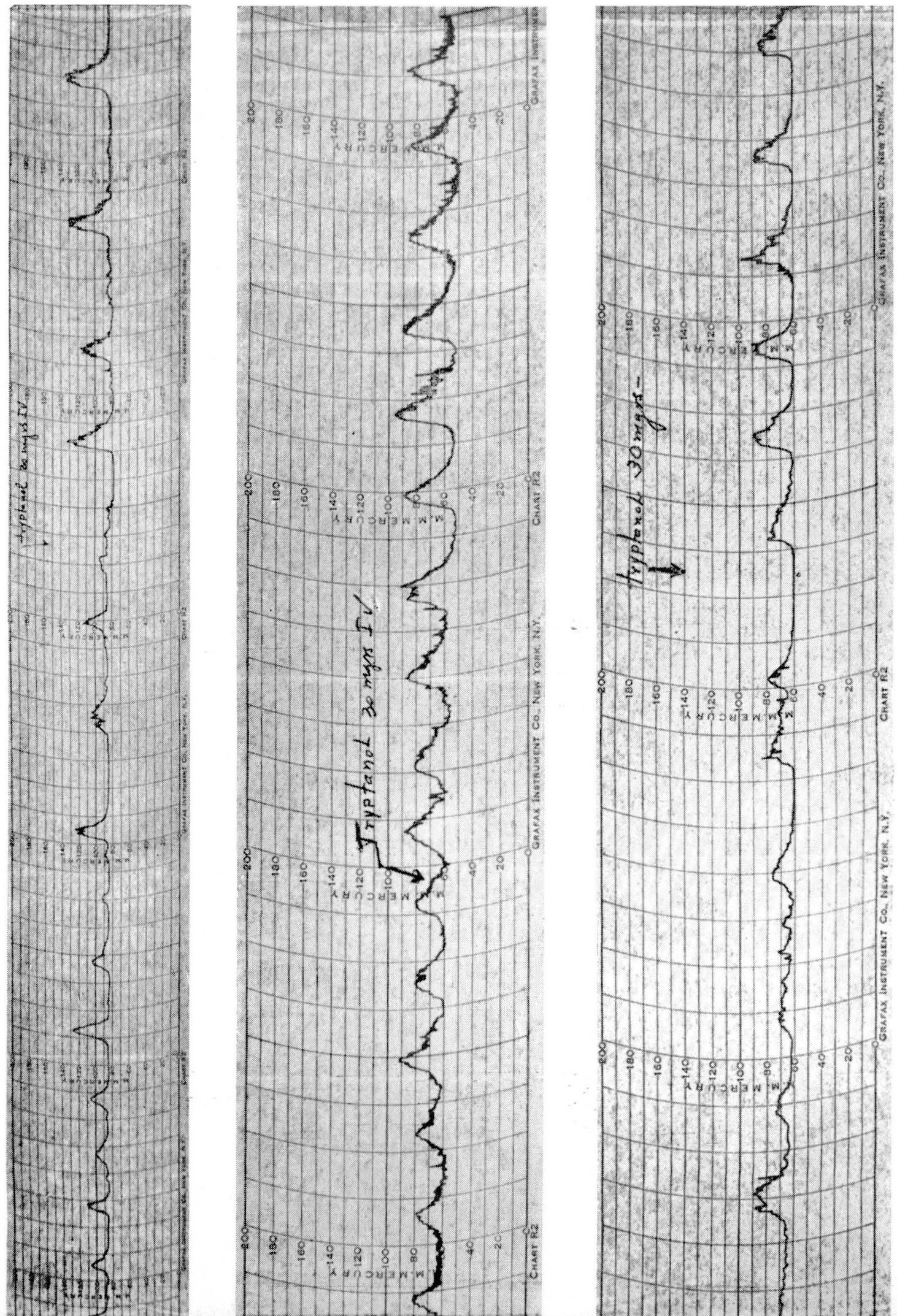


\section{BIBLIOGRAFIA}

1. CALDEYRO-BARCIA B.: Relato oficial presentado al III Congreso Latinoamericano de Obstetricia y Ginecología y al III Congreso Mexicano de Obstetricia y Ginecología. 1958.

2. CORDEY R.: Gynaecología. 154: 334-350. 1962.

3. NAVARRO G., JASSIR C., USCHER O. \& BERNAL G.: Acciones periféricas de dos derivados inmiodibencílicos. Segundo Seminario Colombiano de Farmacología. Medellín. 1963. 